\title{
Mid-term Results of Computer-assisted Cervical Reconstruction for Rheumatoid Cervical Spines
}

Study Design. A retrospective single-center study.

Summary and background. We routinely have used C1/2 transarticular and cervical pedicle screw fixations to reconstruct highly destructed unstable rheumatoid arthritis (RA) cervical lesions. However, there is little data on mid-term results of surgical reconstruction for rheumatoid cervical disorders, particularly, cervical pedicle screw fixation.

Objectives. The purpose of this study was to evaluate the mid-term surgical results of computer-assisted cervical reconstruction for such lesions.

Methods. Seventeen subjects (4 men, 13 women; mean age, $61 \pm 9$ years) with RA cervical lesions who underwent C1/2 transarticular screw fixation or occipitocervical fixation, with at least 5 years follow-up were studied. A frameless, stereotactic, optoelectronic, CT-based image-guidance system, was used for correct screw placement. Variables including the Japanese Orthopaedic Association (JOA) score, Ranawat class, EuroQol (EQ-5D), atlantodental interval (ADI), and Ranawat values before, and at 2 and 5 years after surgery, were evaluated. Furthermore, screw perforation rates were evaluated.

Results. The lesions included atlantoaxial subluxation (AAS, $n=6)$, AAS + vertical subluxation (VS, $\mathrm{n}=7$ ), and AAS + VS + subaxial subluxation $(\mathrm{n}=4)$. There was significant neurological improvement at 2 years after surgery, as evidenced by the JOA scores, Ranawat class, and the EQ-5D utility weight. However, at 5 years after surgery, 
there was a deterioration of this improvement. The Ranawat values before, and at 2 and 5 years after surgery, were not significantly different. Major screw perforation rate was 2.1\%. No neural and vascular complications associated with screw insertion were observed.

Conclusions. Subjects with rheumatoid cervical lesions who underwent C1-C2 transarticular screw fixation or occipitocervical fixation using a pedicle screw had significantly improved clinical parameters at 2 years after surgery. However, there was a deterioration of this improvement at 5 years post surgery. 


\section{Introduction}

Rheumatoid arthritis (RA) is a chronic inflammatory disease of the joints, with an unknown etiology, and is characterized by erosive synovitis. Synovial inflammation can lead to joint erosions and erosions of periarticular soft tissues, which are integral for joint stability. Damage to ligaments and joints can cause different types of instability $[1,2]$. The involvement of the cervical spine in patients with RA is a common complication that often results in anatomical deformities, particularly those of the upper cervical spine [3]. Radiological cervical spine involvement can be present in up to $86 \%$ of all RA patients $[4,5]$. In the early stage of the disease, there is an isolated atlantoaxial subluxation (AAS). With further progression, osseous destruction of the joints can lead to vertical instability. While the involvement of the middle and lower cervical spine can cause subaxial instability, neurological deficits can occur at any time [6]. The incidence of vertical subluxation (VS) as well as subaxial subluxation (SAS) was significantly increased during a minimum 5-year follow up period [7]. These disorders in RA could result in severe symptoms, including occipital/neck pain, quadriplegia, and paralysis of respiratory muscles. In such cases, C1-C2 transarticular screw fixation or occipitocervical fixation and neurological decompression may be indicated.

We have used a CT-based computer navigation system for planning, and screw insertion in C1-C2 transarticular screw or cervical pedicle screw fixation, in order to avoid severe injury to the neural or vascular structures. We have reported good results of surgical reconstruction using this method, 2 years post surgery [8]. However, there is little data on mid-term results ( $>5$ years of follow up) of surgical reconstruction for rheumatoid cervical disorders, particularly, cervical pedicle screw fixation. The purpose of this study was to evaluate the mid-term surgical results of computer-assisted surgical 
reconstruction using transarticular or cervical pedicle screw for cervical spine affected by RA.

\section{Materials and Methods}

Between January 2000 and June 2006, 21 patients underwent C1-C2 transarticular screw fixation or occipito-cervical (or thoracic) fixation using a pedicle screw for RA cervical lesions [AAS, AAS + VS, or AAS + VS + SAS] in our hospital. Of these, 2 patients died and 2 were lost to follow up. We selected 17 patients (4 men and 13 women; mean age, $61 \pm 9$ years [mean \pm S.D.]) with RA cervical lesions who underwent C1-C2 transarticular screw fixation or occipito-cervical (or thoracic) fixation using pedicle screw, with at least 5 years follow up. The follow-up rate was $81 \%$. The clinical profiles and surgical details of the patients are shown in Table 1. A frameless, stereotactic, optoelectronic, CT-based image-guidance system (Stealth Station and Stealth Station TREON ${ }^{\mathrm{TM}}$; Medtronic, Sofamor Danek, Memphis, TN, USA) was used for correct screw placement. This study was carried out with the approval of the institutional ethics committee of our hospital.

The following surgical procedures were performed: C1-C2 transarticular screw fixation (Magerl and Brooks procedure; Trans Bone Screw; KiscoMedica, St Priest, France) [9] in patients with AAS, and occipitocervical or occipitothoracic fusion using the Olerud cervical system (Nord Opedic, Askim, Sweden) or RRS Loop Spinal System (Robert Leid, Tokyo, Japan) in those with AAS, VS, or AAS + VS + SAS [8]. We performed C1-C2 transarticular screw fixation (Magerl and Brooks procedure) for 
reducible AAS without VS. Occipito-C2 or C3 fusion + C1 laminectomy were performed for irreducible AAS and in cases showing Ranawat value $<13 \mathrm{~mm}$ or medullary compression on MRI. C1 laminectomy + O-C or O-T fusion were fixed up to the vertebral level of SAS for AAS+VS+SAS.

The Japanese Orthopaedic Association (JOA) score [10], Ranawat class [11], and EuroQol (EQ-5D) utility weight [12] were used for the clinical evaluation of cervical disorders with RA before surgery and at 2 and 5 years after surgery. The Ranawat classification is defined as follows: class 1 , no neural deficit; class 2, subjective weakness with hyper-reflexia and dysesthesia; class 3A, objective findings of paresis and long-tract signs, but ambulation is possible; and class $3 \mathrm{~B}$, quadriparesis with resultant inability to walk or feed oneself [11]. The EQ-5D questionnaire consists of 5 sections covering the health domains of mobility, self-care, usual activity, pain, and anxiety/depression. Each domain is rated according to 3 levels of severity: no problems (1 point), some or moderate problems (2 points), and severe problems (3 points). Utility weights can then be attached to the EQ-5D health state provided by the questionnaire; these weights are incrementally arranged on a scale wherein full health and death are represented by scores of 1 and 0 , respectively. Some severe health states are given negative scores, indicating that the patient's relative levels of dysfunction, as measured by the parameters noted above (EQ-5D), may be considered worse than death from social perspective [12].

Radiologic evaluations were performed for measuring the atlantodental interval (ADI) and Ranawat value before surgery and at 2 and 5 years after surgery. Additionally, the cervico-medullary (CM) angle, subtended by lines drawn parallel to the ventral surfaces of the medulla and upper cervical cord [13], was measured by 
preoperativeT2-weighted sagittal MRI. Postoperative CM angle was also measured in the patients who were performed postoperative MRI.

Furthermore, as a sub analysis, patients with improved Ranawat values at 5 years after surgery were compared with patients having the same or worse status relative to the status before surgery by evaluating JOA score, Ranawat class, and EQ-5D utility weights.

All patients underwent reconstruction CT scans (Siemens SOMATOM Sensation 16; Siemens Asahi Meditec Inc., Shinagawa, Tokyo, Japan) of instrumented levels after surgery. Pedicle screw perforations of cervical pedicles were evaluated by axial CT images with $1.25 \mathrm{~mm}$ slice thickness. Screw insertion status was classified as follows: grade 1 (no perforation), screw is accurately inserted in pedicle; grade 2 (minor perforation), perforation of less than $50 \%$ of screw diameter; grade 3 (major perforation), perforation of $50 \%$ of screw diameter or more.

The data were analyzed by a Wilcoxon signed rank sum test using SPSS software (SPSS Japan Inc., an IBM company, Tokyo, Japan); a P-value of <.05 was defined as significant.

\section{Results}

The mean follow-up period was 82.0 months. The mean preoperative duration of RA in these patients was 16.8 years. The number of subjects according to Steinbrocker stage and class is shown in Table 1 . The cervical spine disorders in this study included AAS $(n=6)$, AAS + VS $(n=7)$, and AAS + VS + SAS $(n=4)($ Table 1$)$ 
The average time taken for the surgical procedure was $240 \pm 101 \mathrm{~min}$. The average blood loss volume was $326 \pm 211 \mathrm{~mL}$. Fusion area of these patients included C1-C2 (n = 6; M/F, 2/4), C0-C2 or C3 (n = 5; M/F, 0/5), and C0-C4 to T2 (n = 6; M/F, 2/4).

\section{Clinical assessment}

The JOA scores significantly improved 2 years post surgery. However, at 5 years after surgery, there was deterioration in this improvement, and the JOA scores were not significantly different from those before surgery (Figure 1). The number of subjects in Ranawat classes I, II, IIIA, and IIIB before and after surgery is shown in Figure 2. There was significant improvement in the EQ-5D utility weight 2 years post surgery. The EQ-5D utility weight at 5 years was not significantly different from that before surgery (Figure 3(a)).

\section{Radiographic assessment}

The ADI showed a significantly improved value 2 years and 5 years after surgery, as compared to that before surgery (Figure 3(b)). The Ranawat value was not significantly different at 2 years or 5 years after surgery, as compared to that before surgery (Figure 3(c)). The mean preoperative ADI in the flexion and extension were $8.9 \pm 4.7$ (range, 1-20 degrees) and $4.0 \pm 2.4$ degrees (range, 1-8 degrees), respectively. The mean CM angle was $143.7 \pm 11.1$ degrees (range, 128-175 degrees) before surgery. In the patients who was performed postoperative MRI ( $\mathrm{n}=13$ ), postoperative CM angle was $157.9 \pm 9.1$ degrees (range, 147-167 degrees). Major screw perforation rate (Grade 3) was 2.1\% (1/47). The screw perforation rate of grade 2 plus 3 was 6.4\% (3/47). No neural and vascular complications associated with screw insertion were observed. Two (11.8\%) 
patients were occurred the development of SAS after surgery. However, there was no patient who needed to be performed revision surgery. All patients achieved bony fusion and none required a reoperation.

\section{Sub analysis of the clinical assessments according to changes in the Ranawat value}

In the patients whose Ranawat value at 5 years after surgery were improved, compared to before surgery (improved group, $n=7$ ), preoperative JOA score was improved 5 years after surgery, not significantly. On the other hand, in the patients whose Ranawat value at 5 years after surgery were same status or worsened, compared to before surgery (non-improved group, $\mathrm{n}=10$ ), preoperative JOA score was very slightly improved 5 years after surgery (Figure 4(a)). The number of subjects in Ranawat classes I, II, IIIA, and IIIB at 5 years after surgery were 1, 4, 1, and 1, respectively, in improved group; and $0,1,6$, and 3, respectively, in non-improved group. In non-improved group, the percentage of IIIA, and IIIB was higher. In the improved group, EQ-5D utility weights before surgery and at 5 years after surgery were $0.48 \pm 0.18$ and $0.47 \pm 0.21$ respectively. In the non-improved group, EQ-5D utility weights before surgery and at 5 years after surgery were $0.41 \pm 0.31$ and $0.42 \pm 0.26$, respectively (Figure 4(b)). The results of EQ-5D were not almost different between these groups.

Clinical data, radiological data, and surgical procedures were evaluated by type and classification of cervical spine disorders. Preoperative JOA score were as follows: AAS, 11.3; AAS + VS, 9.9; and AAS + VS + SAS, 3.2. Preoperative utility weights were as follows: AAS, 0.57; AAS + VS, 0.46; and AAS + VS + SAS, 0.095. The number of patients presenting at a particular Steinbrocker's stage were as follows: AAS stage I, 1 patient; stage III, 4 patients; AAS + VS stage III, 4 patients; stage IV, 3 patients; AAS + 
VS + SAS stage III, 1 patient; and stage IV, 3 patients. The number of patients presenting at a particular Steinbrocker's class were as follows: AAS class II, 3 patients; class IV, 2 patients; AAS + VS class II, 2 patients; class III, 4 patients; class IV, 1 patient; AAS + VS + SAS class III, 1 patient; class IV, 2 patients.

All patients with AAS were surgically stabilized using C1-C2 transarticular screw fixation and all patients with AAS + VS or AAS + VS + SAS were surgically stabilized using occipitocervical or occipitothoracic fusion. The mean number of fusion level(s) was as follows: AAS, 1.0 intervertebral level; AAS + VS, 3.4 intervertebral levels; and AAS + VS + SAS, 8.3 intervertebral levels. Preoperative ADI were as follows: AAS, $9.2 \mathrm{~mm}$; AAS + VS, $6.3 \mathrm{~mm}$; and AAS + VS + SAS, $4.8 \mathrm{~mm}$. ADI at 5 years after surgery were as follows: AAS, $3.3 \mathrm{~mm}$; and AAS + VS, $4.6 \mathrm{~mm}$; AAS + VS + SAS, 4.7 mm. Preoperative Ranawat values were as follows: AAS, 13.2 mm; AAS + VS, 9.3 mm; and AAS + VS + SAS, 8.7 mm. Ranawat values at 5 years after surgery were as follows: AAS, $14.5 \mathrm{~mm}$; AAS + VS, $9.0 \mathrm{~mm}$; and AAS + VS + SAS, $8.3 \mathrm{~mm}$.

\section{Case Presentation}

Case 16: A 54-year-old woman with AAS secondary to destructive rheumatoid arthritis

A preoperative radiograph revealed an ADI of $12 \mathrm{~mm}$. Preoperative JOA score was 11.5 points, and the EQ-5D utility weight was 0.649. C1-C2 transarticular screw fixation was performed. The AAS was found to be corrected to within normal limits after surgery. Two-year postoperative radiographs demonstrated an ADI of $3 \mathrm{~mm}$. At this time, JOA score was 14.5 points and the EQ-5 D utility weight was 0.649 . At 5 years after surgery, ADI was $3 \mathrm{~mm}$, JOA score was 16 points, and the EQ-5D utility weight was 
0.649. Notably, JOA score improved 5 years after surgery (Figure 5).

\section{Case 15: A 68-year-old woman with AAS and VS secondary to destructive rheumatoid arthritis}

A preoperative radiograph revealed an ADI of $8 \mathrm{~mm}$ and a Ranawat value of $5 \mathrm{~mm}$. Preoperative JOA score was 12.5 points, and the EQ-5D utility weight was 0.724 . Occipitocervical (C0-3) fusion and C1 laminectomy were performed. The VS did not respond well to corrective surgery. Two-year postoperative radiographs demonstrated an ADI of $8 \mathrm{~mm}$ and a Ranawat value of $8 \mathrm{~mm}$. JOA score was 15 points and EQ-5D utility weighting was 1.000 at that time. Five years after surgery, measurements demonstrated an ADI of $8 \mathrm{~mm}$ and a Ranawat value of $6 \mathrm{~mm}$. JOA scoring was 11 points, and the EQ-5D utility weight was 0.596. The Ranawat value, JOA score, and EQ-5D utility weight had therefore deteriorated (Figure 6).

\section{Case 11: A 53-year-old man with AAS, VS and SAS secondary to destructive rheumatoid arthritis}

A preoperative radiograph revealed an ADI of 3.5 (maximum flexion view) and $1 \mathrm{~mm}$ (neutral position view). The patient presented with a Ranawat value of $9 \mathrm{~mm}$ and C5-C6 SAS. The preoperative JOA score was 3.5 points, and the EQ-5D utility weight was -0.062. Occipito-cervical (C0-7) fusion with C1 laminectomy and C3-7 laminoplasty were performed. Two-year postoperative radiographs demonstrated an ADI of $1 \mathrm{~mm}$ and a Ranawat value of $7 \mathrm{~mm}$. The JOA score was 11 points and EQ-5D utility weighting was 0.485 at that time. Five years after surgery, ADI was $1 \mathrm{~mm}$, Ranawat value was 7 mm, and JOA score was 9 points (Figure 7). 


\section{Discussion}

Cervical disorders in RA could result in severe symptoms, including occipital/neck pain, quadriplegia, and paralysis of respiratory muscles. In such cases, cervical or occipitocervical reconstruction and neurological decompression are performed. With conservative treatment, the prognosis for patients with destructive cervical lesions and myelopathy with RA has been reported to be poor [14-18]. Paimela et al. showed an early involvement of the cervical spine in the course of RA, often within the first 2 years of diagnosis [19]. Craniocervical complications arise in $30-50 \%$ of the patients who have had RA for $>7$ years, while atlantoaxial subluxation with myelopathy has been shown to develop in $2.5 \%$ of those with RA for $>14$ years [20]. In our study, the mean RA duration of the patients before surgery was 16.8 years.

For cervical disorders in RA, posterior procedures using sublaminar wiring or hook systems have been employed. However, these sometimes result in failure of reduction and/or non-union [21,22]. Compared with conventional posterior fusion techniques, innovative methods such as C1-C2 transarticular and cervical pedicle screw techniques provide greater biomechanical stability $[23,24]$. However, because of the severe spinal deformity and small anatomical size of the vertebrae, including the pedicle, found in the majority of RA cervical lesions, pedicle screw fixation procedures are technically demanding and pose the potential risk of neurovascular injuries [25-27]. Computer-assisted techniques were introduced in spine surgery in the 1990s to improve accuracy and safety of operative procedures [28,29]. In 1996, laboratory testing and 
clinical application of computer-assisted spine surgery was started [30,31]. To improve the accuracy of screw placement, we adopted an image-guidance system for surgical reconstruction of RA cervical spine lesions.

In patients who underwent surgical procedures for cervical spondylotic myelopathy, short-term (immediately after surgery to 1.8 years after surgery) improvements in clinical outcomes were shown to be reduced at the final follow-up (range, 2-15 years after surgery) [32-34], possibly because of advancing age. Among our subjects with RA cervical lesions who underwent C1-C2 transarticular screw fixation or occipitocervical fixation, the neurological findings, as measured by JOA scores significantly improved at 2 years after surgery. However, there was a deterioration of this improvement at 5 years after surgery. The quality of life, as measured by EQ-5D utility weight, of the subjects also improved at 2 years after surgery but was reduced at 5 years. The mean subject age, which was 61 years at the time of surgery, naturally became approximately 66 years after 5 years. Therefore, progression of joint degeneration in vertebrae or extremities, or decrease in motor function because of osteoporosis, especially for women, should be the major cause of neurological symptoms or decreased QOL. The deterioration of the outcome at 5 years as compared to 2 years post surgery may be attributable to the increase in age of the subjects or the destruction of other joints. Furthermore, in 3 patients whose medication was changed because of high disease activity, the EQ-5D utility weight at 5 years after surgery was worsened compared to that at 2 years after surgery or had returned to the pre-surgical status. The rapidity of disease activity may also be related to the deterioration of the outcome.

Patients with RA cervical lesions who did not undergo any surgical procedure showed no neural improvement, and in fact, aggravation of their condition was observed 
in $76 \%$ of the cases during the follow-up period. All the patients were bedridden within 3 years after the onset of myelopathy, and the survival rate was $0 \%$ in the first 8 years [35]. Our results show that the quality of life, as well as the number of patients that could not ambulate, returned to the preoperative level 5 years post surgery. However, the JOA scores at 5 years post surgery were better than that before surgery. Our results suggest a beneficial effect of surgical procedures vs. conservative treatments, for treating RA cervical lesions. However, the increase in subject age or the destruction of other joints because of long-standing RA may have caused mid-term deterioration of clinical results after surgery. It is important to follow-up patients for more than 5 years after surgery.

In our study, ADI improved significantly at 2 years after surgery, and the correct position was maintained at 5 years after surgery. However, there was no significant change in the Ranawat value at either 2 or 5 years after surgery. Correction of VS may lead good long-term result. So, we performed comparison of the patients whose Ranawat value at 5 years after surgery were improved and were same status or worsened, compared to before surgery, by evaluating by JOA score, Ranawat class and EQ-5D. JOA score at 5 years after surgery was more improved and the percentage of IIIA, and IIIB was lower in improved group. On the other hand, the results of EQ-5D were not different between these groups. According to these results, It was indicated that it was possible to improve neurologic deficits by maintaining reduction of VS. The prevalence of SAS in nonoperative patients has been reported to be somewhere between $15 \%$ and $22 \%$. In operated patients, the higher incidence $(15 \%-76.5 \%)$ of newly developed SAS after occipitocervical fusion has been reported [36]. In our study, 2 of 17 (11.8\%) patients developed after surgery. The rate of SAS in our study was lower 
than previous reports.

The limitations of this study include lack of a control group, small sample size, various pathologies, and retrospective design. However, on the basis of the outcomes of our 17 patients, we conclude that $\mathrm{C} 1-\mathrm{C} 2$ transarticular screw fixation and occipitocervical fixation using a CT-based navigation system is effective in the treatment of rheumatoid cervical spine disorders.

\section{Conclusion}

Subjects with rheumatoid cervical lesions who underwent C1-C2 transarticular screw fixation or occipitocervical fixation using a pedicle screw had significantly improved clinical parameters at 2 years after surgery. The improved JOA scores showed deterioration at 5 years as compared to 2 years post surgery, although the scores at 5 years post surgery were better than that before surgery. Ranawat classes and EQ-5D at 5 years post surgery were similar to those before surgery.

\section{References}

[1] Halla JT, Fallahi S. Cervical discovertebral destruction, subaxial subluxation, and myelopathy in a patient with rheumatoid arthritis. Arthritis Rheum. 1981;24:944-7. 
[2] McConkey B. Rheumatoid cervical myelopathy. Br Med J (Clin Res Ed). 1982;12:284:1731-2

[3] Halla JT, Hardin JG, Vitek J, Alarcón GS. Involvement of the cervical spine in rheumatoid arthritis. Arthritis Rheum. 1989;32:652-9.

[4] Pellicci PM, Ranawat CS, Tsairis P, Bryan WJ. A prospective study of the progression of rheumatoid arthritis of the cervical spine. J Bone Joint Surg Am. $1981 ; 63: 342-50$.

[5] Smith PH, Benn RT, Sharp J. Natural history of rheumatoid cervical luxations. Ann Rheum Dis. 1972;31:431-9.

[6] Kothe R, Wiesner L, Ruther W. Rheumatoid arthritis of the cervical spine. Current concepts for diagnosis and therapy. Orthopade. 2002;31:1114-22.

[7] Yurube T, Sumi M, Nishida K, Takabatake M, Kohyama K, Matsubara T, Ozaki T, Maeno K, Kakutani K, Zhang Z, Doita M. Progression of cervical spine instabilities in rheumatoid arthritis: a prospective cohort study of outpatients over 5 years. Spine. 2011;36:647-53.

[8] Takahashi J, Shono Y, Nakamura I, Hirabayashi H, Kamimura M, Ebara S, Kato H. Computer-assisted screw insertion for cervical disorders in rheumatoid arthritis. Eur Spine J. 2007;16:485-94.

[9] Magerl F, Seemann PS. Stable posterior fusion of the atlas and axis by transarticular screw fixation. In: Kehr P, Weidner A, eds. Cervical Spine 1. Vienna, Austria: Springer-Verlag. 1987;322-7.

[10] Japanese Orthopaedic Association. Scoring system for cervical myelopathy. J Jpn Orthop Assoc. 1994;68:490-503. 
[11] Ranawat CS, O’Leary P, Pellici P. Cervical spine fusion in rheumatoid arthritis. J Bone Joint Surg Am. 1979;61:1003-10.

[12] EuroQol Group. EuroQol-a new facility for the measurement of health-related quality of life. The EuroQol Group. Health Policy. 1990;16:199-208.

[13] Wang S, Wang C, Passias PG, Li G, Yan M, Zhou H. Interobserver and intraobserver reliability of the cervicomedullary angle in a normal adult population. Eur Spine J. 2009;18:1349-54.

[14] Omura K, Hukuda S, Katsuura A, Saruhashi Y, Imanaka T, Imai S. Evaluation of posterior long fusion versus conservative treatment for the progressive rheumatoid cervical spine. Spine. 2002;27:1336-45.

[15] Marks J, Sharp J. Rheumatoid cervical myelopathy. Q J Med. 1981;50:307-19.

[16] Meijers K, Cats A, Kremer H, Luyendijk W, Onvlee GJ, Thomeer RT. Cervical myelopathy in rheumatoid arthritis. Clin Exp Rheumatol. 1984;2:239-45.

[17] Sunahara N, Matsunaga S, Mori T, Ijiri K, Sakou T. Clinical course of conservatively managed rheumatoid arthritis patients with myelopathy. Spine. 1997;22:2603-7.

[18] Falope ZF, Griffiths ID, Platt PN, Todd NV. Cervical myelopathy and rheumatoid arthritis: a retrospective analysis of management. Clin Rehabil. 2002;16:625-59.

[19] Paimela L, Lassonen L, KanKaanpaa E, Leirisalo-Repo M. Progression of cervical spine changes in patients with early rheumatoid arthritis. J Rheumatol. 1997;24:1280-4.

[20] Moskovich R, Shott S, Zhang ZH. Does the cervical canal to body ratio predict spinal stenosis? Bull Hosp Jt Dis. 1996;55:61-71. 
[21] Santavirta S, Konttinen Y, Laasonen E, Honkanen V, Antti-Poika I, Kauppi M. Ten-year results of operations for rheumatoid cervical spine disorders. J Bone Joint Surg. 1991;73B:116-20.

[22] Sumi M, Kataoka O, Ikeda M, Sawamura S, Uno K, Siba R. Atlantoaxial dislocation: a follow-up study of surgical results. Spine. 1997;22:759-64.

[23] Grob D, Crisco JJ 3rd, Panjabi MM, Wang P, Dvorak J. Biomechanical evaluation of four different posterior atlantoaxial fixation techniques. Spine. 1992;17:480-90.

[24] Kotani Y, Cunningham BW, Abumi K, McAfee PC. Biomechanical analysis of cervical stabilization systems: an assessment of transpedicular screw fixation in the cervical spine. Spine. 1994;17:2529-39.

[25] Fuji T, Oda T, Kato Y, Fujita S, Tanaka M. Accuracy of atlantoaxial transarticular screw insertion. Spine. 2000;25:1760-4.

[26] Madawi AA, Casey AT, Solanki GA, Tuite G, Veres R, Crockard HA. Radiological and anatomical evaluation of the atlantoaxial transarticular screw fixation technique. J Neurosurg.1997;86:961-8.

[27] Wright NM, Lauryssen C. Vertebral artery injury in C1-2 transarticular screw fixation: results of a survey of the AANS/CNS Association of Neurological Surgeon/Congress of Neurological Surgeons. J Neurosurg. 1998;88:634-40.

[28] Amiot LP, Labelle H, DeGuise JA, Sati M, Brodeur P, Rivard CH. Computer-assisted pedicle screw fixation. A feasibility study. Spine. 1995;20:1208-12.

[29] Nolte LP, Zamorano LJ, Jiang Z, Wang Q, Langlotz F, Berlemann U. Image-guided insertion of transpedicular screws. A laboratory set-up. Spine. 1995;20:497-500. 
[30] Kamimura M, Ebara S, Itoh H, Tateiwa Y, Kinoshita T, Takaoka K. Accurate pedicle screw insertion under control using a computer-assisted image guiding system: Laboratory test and clinical study. J Orthop Sci. 1999;4:197-206.

[31] Kamimura M, Ebara S, Itoh H, Tateiwa Y, Kinoshita T, Takaoka K. Safe and accurate cervical pedicle screw insertion guided by a computer assisted image-guidance system. J Spinal Disord. 2000;13:218-25.

[32] Higashino K, Katoh S, Sairyo K, Sakai T, Kosaka H, Yasui N. Preservation of C7 spinous process does not influence the long-term out come after laminoplasty for cervical spondylotic myelopathy. Int Orthop. 2006;30:362-5.

[33] Ishii M, Wada E, Ishii T, Kawai H, Kaneko N, Fuji T. Laminoplasty for patients aged 75 years or older with cervical myelopathy. J Orthop Surg (Hong Kong). 2008;16:211-4.

[34] Kimura I, Shingu H, Nasu Y. Long-term follow-up of cervical spondylotic myelopathy treated by canal by canal-expansive laminoplasty. J Bone Joint surg Br. 1995;77:956-61.

[35] Matsunaga S, Sakou T, Onishi T, Hayashi K, Taketomi E, Sunahara N, Komiya S. Prognosis of patients with upper cervical lesions caused by rheumatoid arthritis: comparison of occipitocervical fusion between c1 laminectomy and nonsurgical management. Spine. 2003;28:1581-7.

[36] Ishii K, Matsumoto M, Takahashi Y, Okada E, Watanabe K, Tsuji T, Takaishi H, Nakamura M, Toyama Y, Chiba K. Risk factors for development of subaxial subluxations following atlantoaxial arthrodesis for atlantoaxial subluxations in rheumatoid arthritis. Spine. 2010;35:1551-5. 


\section{Figure Legends}

Figure 1: Evaluation of JOA scores

The JOA scores before and 2 and 5 years after surgery were $9.3 \pm 1.0,12.8 \pm 0.5$ (P $=0.001$, compared to the pre surgery score), and $10.7 \pm 0.8$, respectively.

Figure 2: The number of subjects in Ranawat classes

The number of subjects in Ranawat classes I, II, IIIA, and IIIB before surgery were 0,5 , 8 , and 4 , respectively; $1,6,8$, and 2, respectively, at 2 years after surgery; and $1,5,7$, and 4, respectively, at 5 years after surgery

Figure 3: Evaluation of EQ-5D utility weight, ADI, and Ranawat value

(a) The EQ-5D utility weight was $0.44 \pm 0.06$ before surgery, $0.58 \pm 0.06$ at 2 years after surgery ( $\mathrm{P}=0.028$, compared to pre surgery value), and $0.44 \pm 0.06$ at 5 years after surgery. (b) ADI was $7.0 \pm 1.1 \mathrm{~mm}$ before surgery, $3.5 \pm 0.4 \mathrm{~mm}$ ( $\mathrm{P}=0.004$ compared to the preoperative value) at 2 years after surgery, and $4.1 \pm 0.4 \mathrm{~mm}(\mathrm{P}=0.024$ compared to the preoperative value) at 5 years after surgery. (c) The Ranawat value was $10.5 \pm 0.8$ $\mathrm{mm}$ before surgery, $11.5 \pm 0.9 \mathrm{~mm}$ at 2 years after surgery, and $10.7 \pm 0.9 \mathrm{~mm}$ at 5 years after surgery.

Figure 4: Sub analysis of JOA score and EQ-5D utility weight 
(a) In improved group, JOA score before surgery and at 5 years after surgerywere $9.1 \pm$ 4.3 and $11.8 \pm 2.0$ respectively. In non-improved goup, JOA score before surgery and at 5 years after surgerywere $9.4 \pm 4.3$ and $9.9 \pm 3.9$ respectively. (b) In improved group, EQ-5D utility weight before surgery and at 5 years after surgerywere $0.48 \pm 0.18$ and $0.47 \pm 0.21$ respectively. In non-improved goup, EQ-5D utility weight before surgery and at 5 years after surgerywere $0.41 \pm 0.31$ and $0.42 \pm 0.26$ respectively.

Figure 5: Case 16

(a) A preoperative radiograph revealed an ADI of $12 \mathrm{~mm}$ and a Ranawat value of $12 \mathrm{~mm}$.

(b) C1-C2 transarticular screw fusion was performed. The AAS was corrected after surgery. At 2 years after surgery, ADI was $3 \mathrm{~mm}$. (c) Correction of AAS was maintained at 5 years after surgery. (d) Preoperative MRI revealed spinal cord compression at the C1/2 level.

Figure 6: Case 15

(a) The preoperative radiograph revealed an ADI of $8 \mathrm{~mm}$ and Ranawat value of $5 \mathrm{~mm}$. (b) 2 years after surgery, radiographs showed an ADI of $8 \mathrm{~mm}$ and a Ranawat value of 8 mm. (c) 5 years after surgery, the ADI was $8 \mathrm{~mm}$ and the Ranawat value was $6 \mathrm{~mm}$. (d) Preoperative MRI revealed compression of the medulla oblongata by VS. (e) Postoperative MRI showed that the medulla oblongata was decompressed. 
Figure 7: Case 11(a) The preoperative radiograph revealed an ADI of $1 \mathrm{~mm}$ and a Ranawat value of $9 \mathrm{~mm}$. (b) C0-7 fusion was performed. Two years after surgery, radiographs showed that ADI was $1 \mathrm{~mm}$ and the Ranawat value was $7 \mathrm{~mm}$. (c) At 5 years after surgery, the ADI was $1 \mathrm{~mm}$ and the Ranawat value was $7 \mathrm{~mm}$. (d) The preoperative MRI showed that the spinal cord was compressed from C3 to C7. 


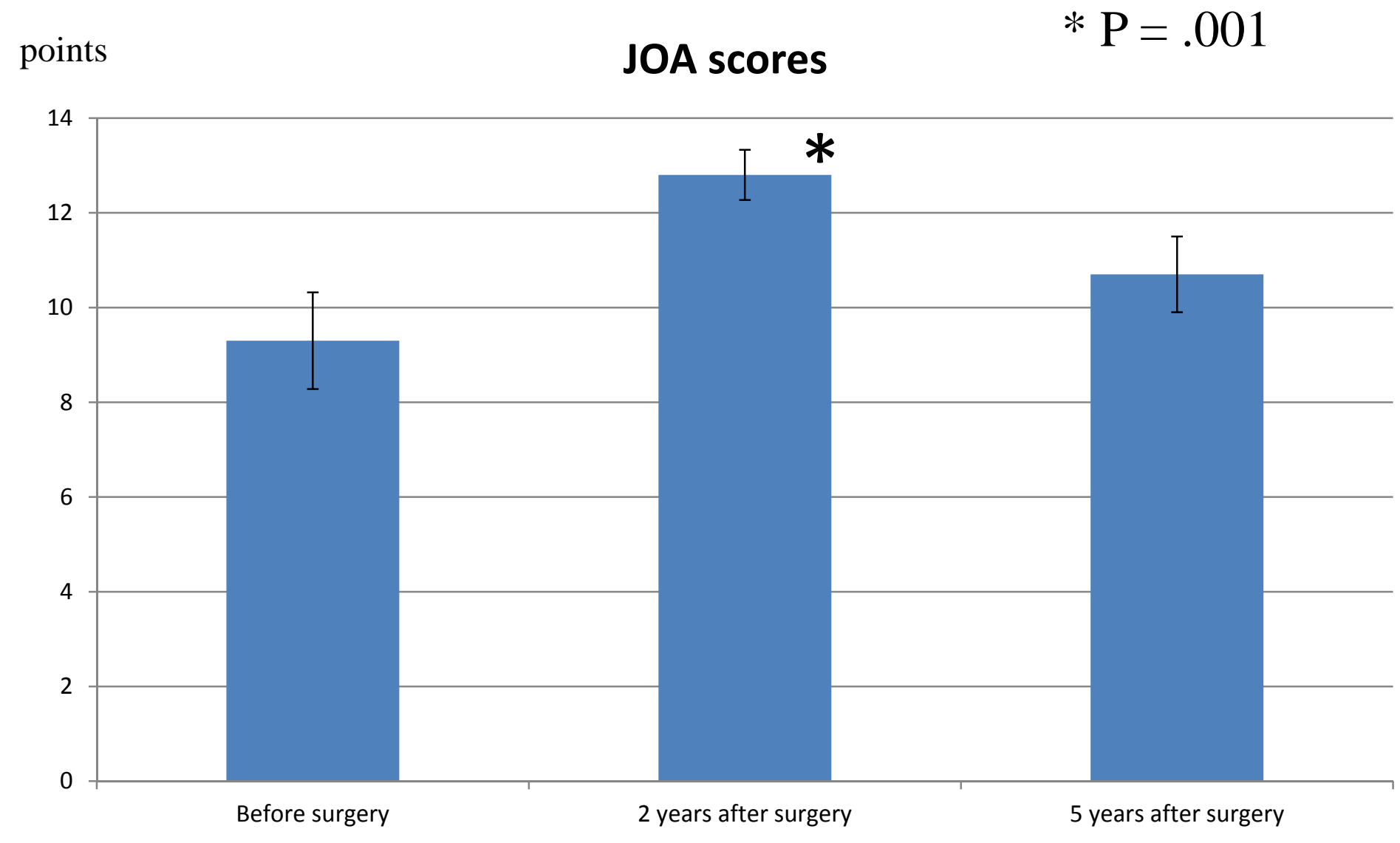

Figure 1

Mean \pm standard error 


\section{Ranawat class}

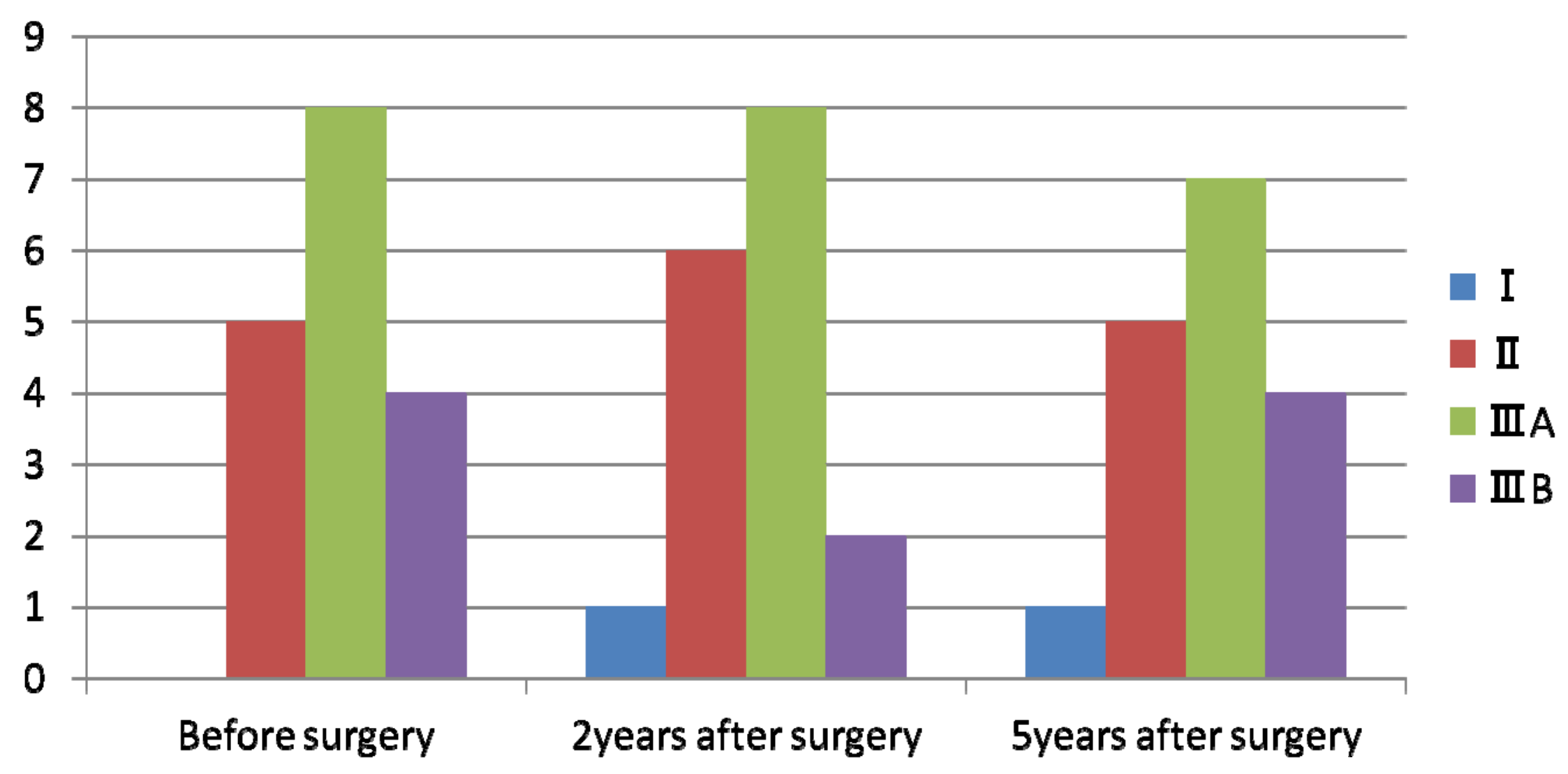

Figure 2 


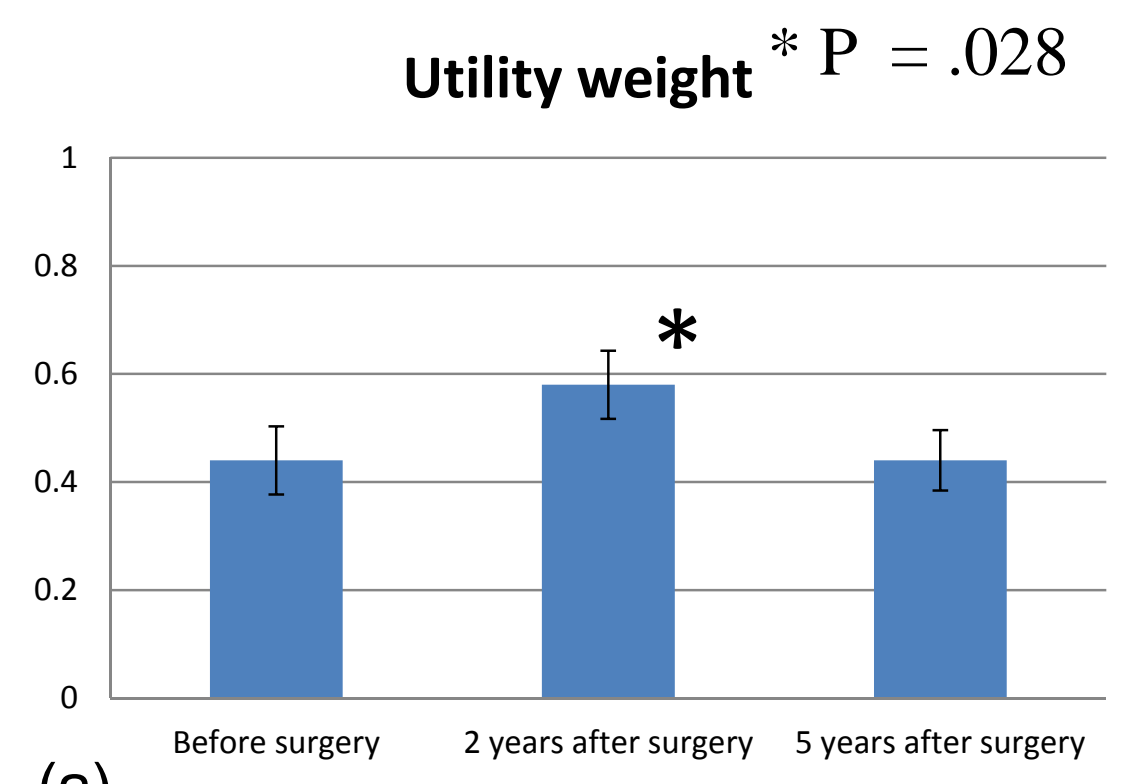

(a)
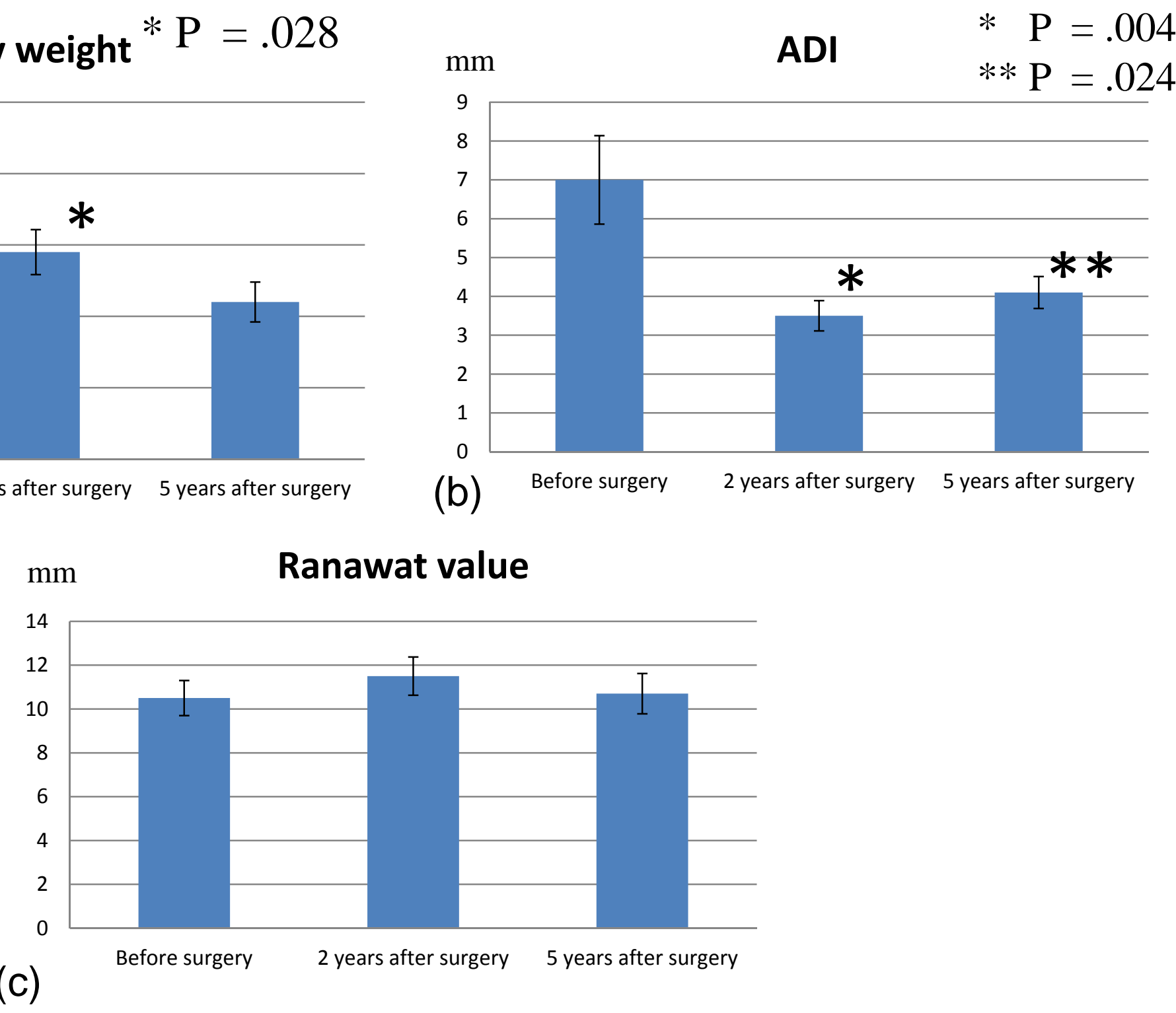

Figure 3

Mean \pm standard error 
(a)

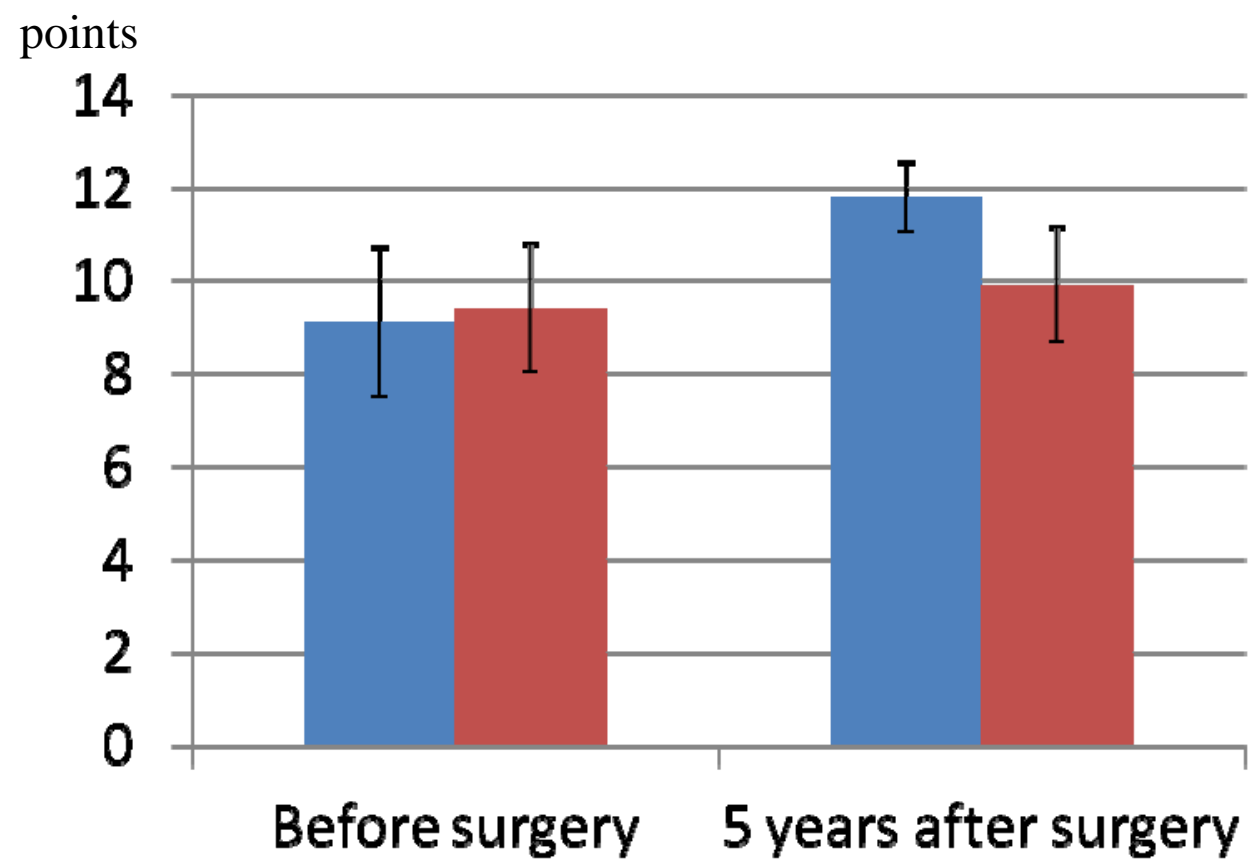

Improved group

Non-improved group

(b)

Figure 4

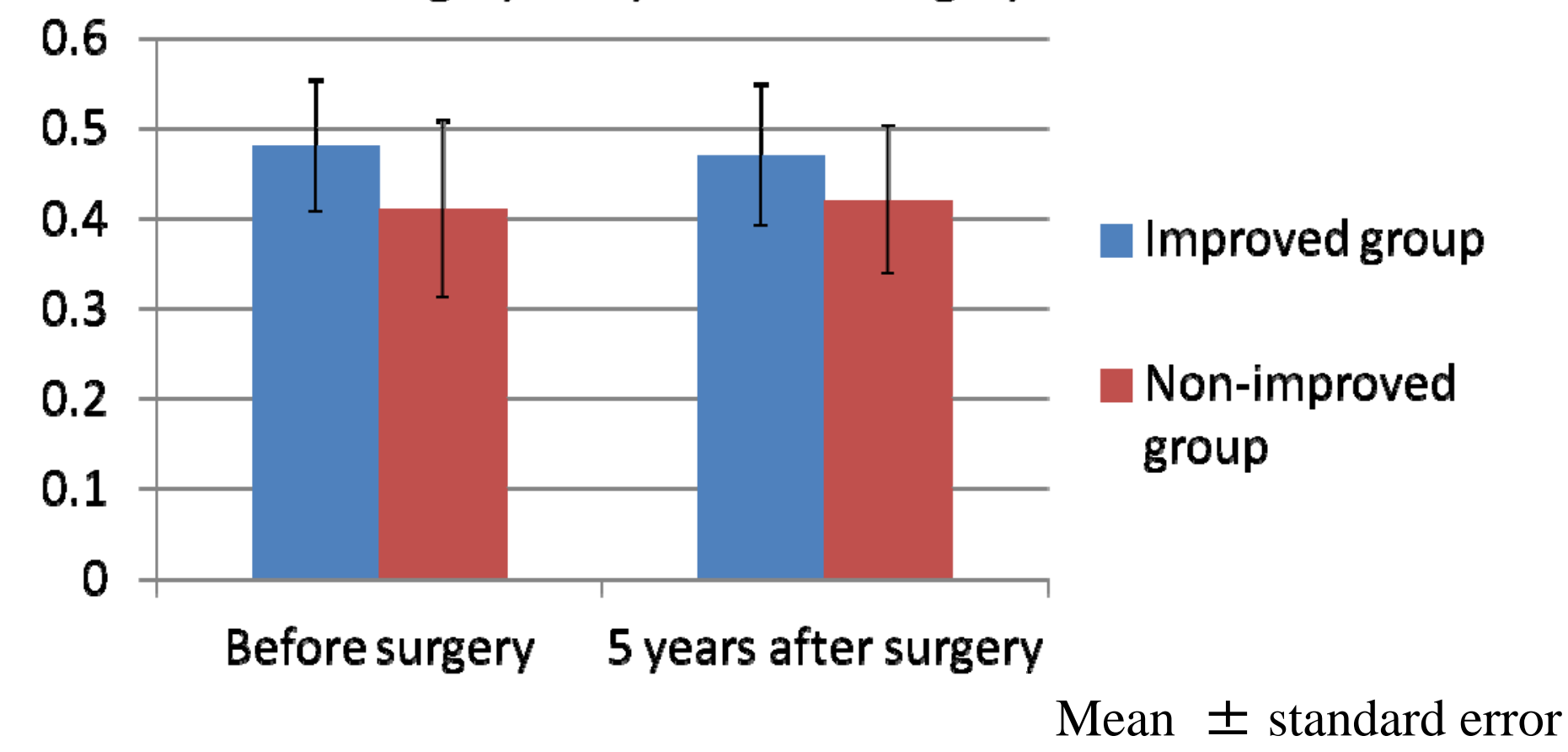




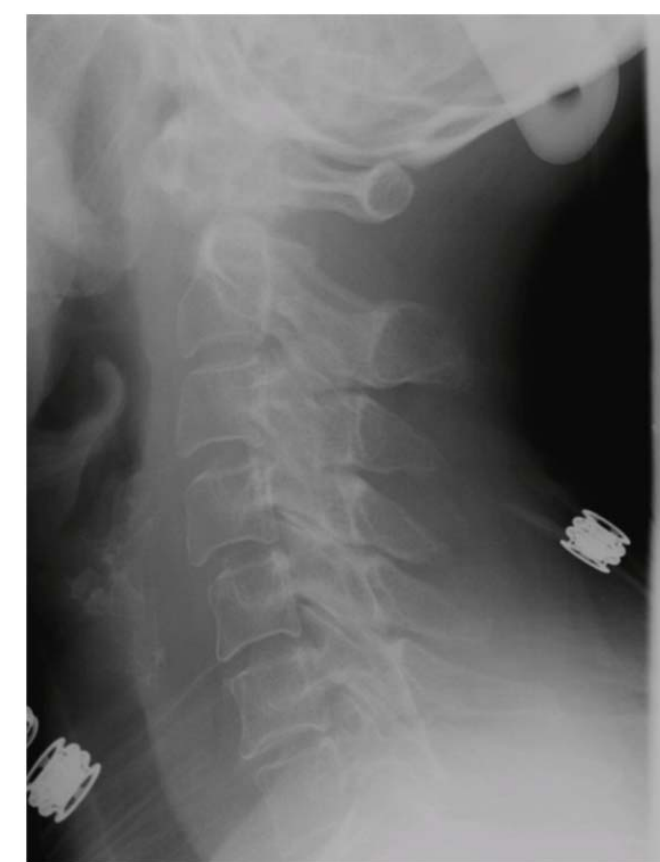

(a) Before surgery

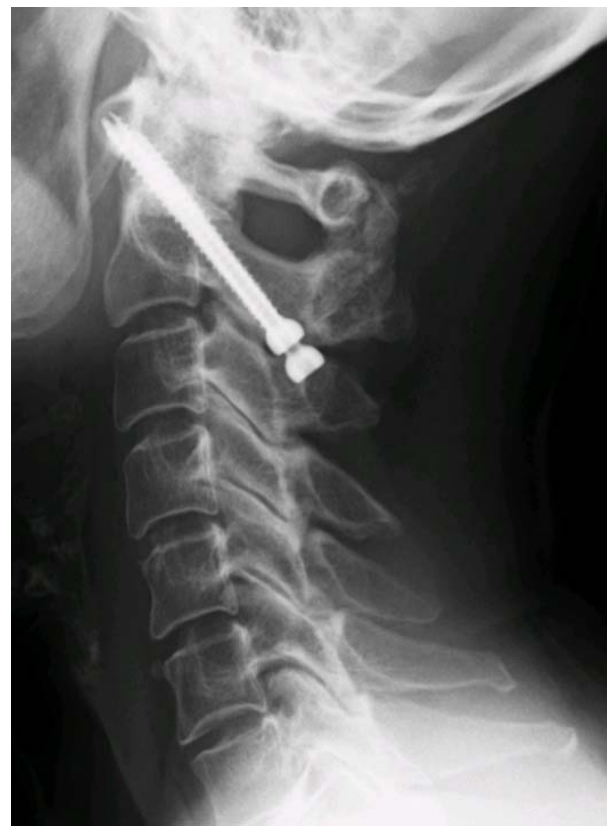

(c) 5 years after surgery

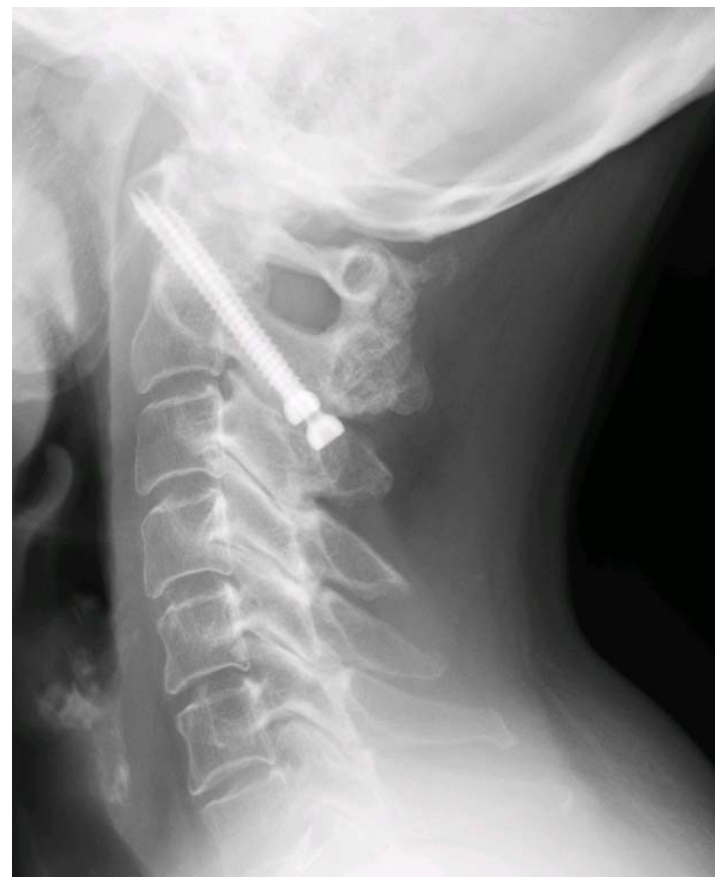

(b) 2 years after surgery

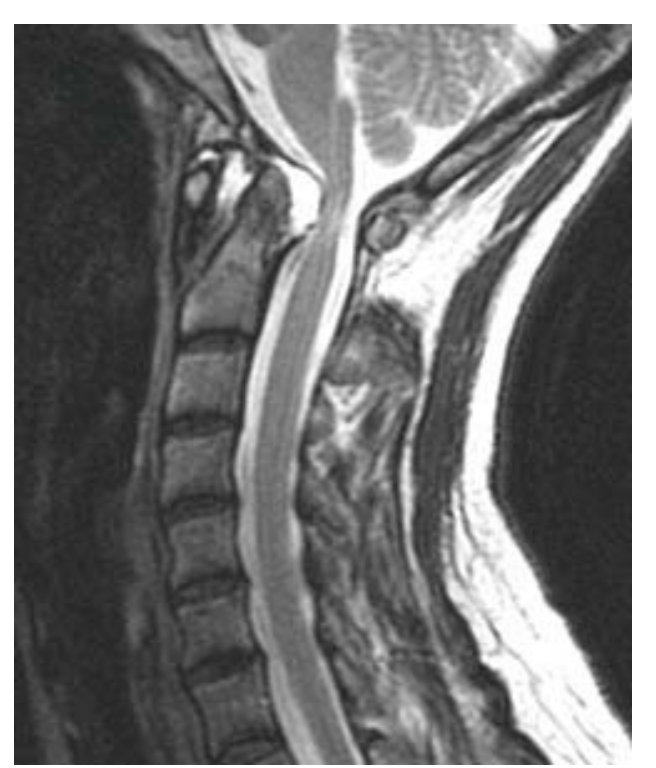

(d) Preoperative MRI 


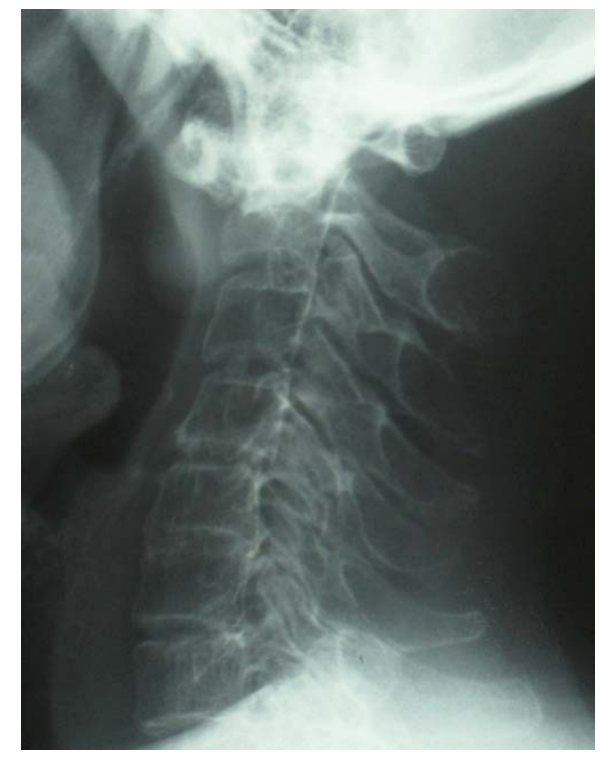

(a) Before surgery

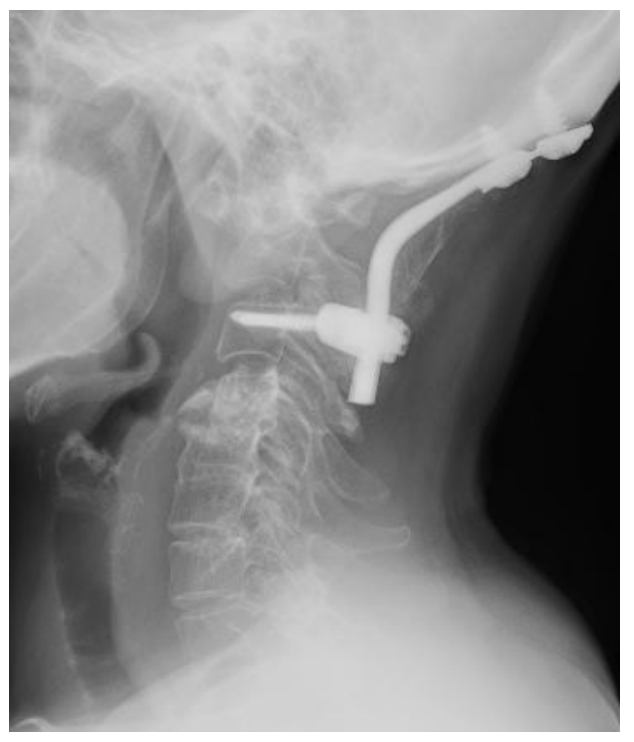

(b) 2 years after surgery

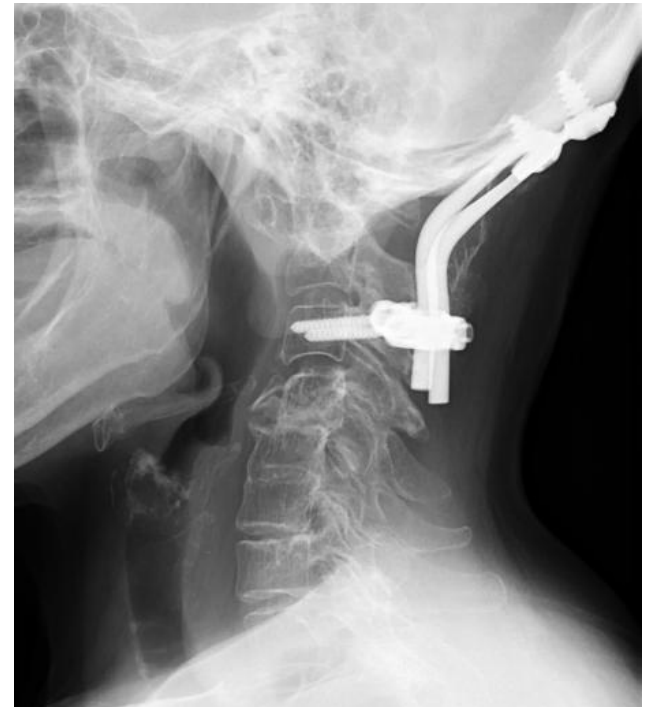

(c) 5 years after surgery

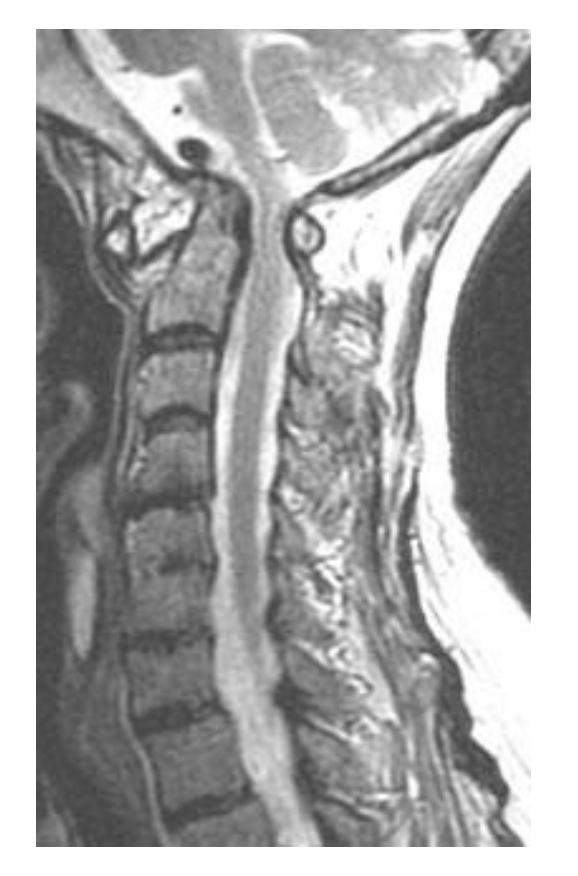

(d) Before surgery

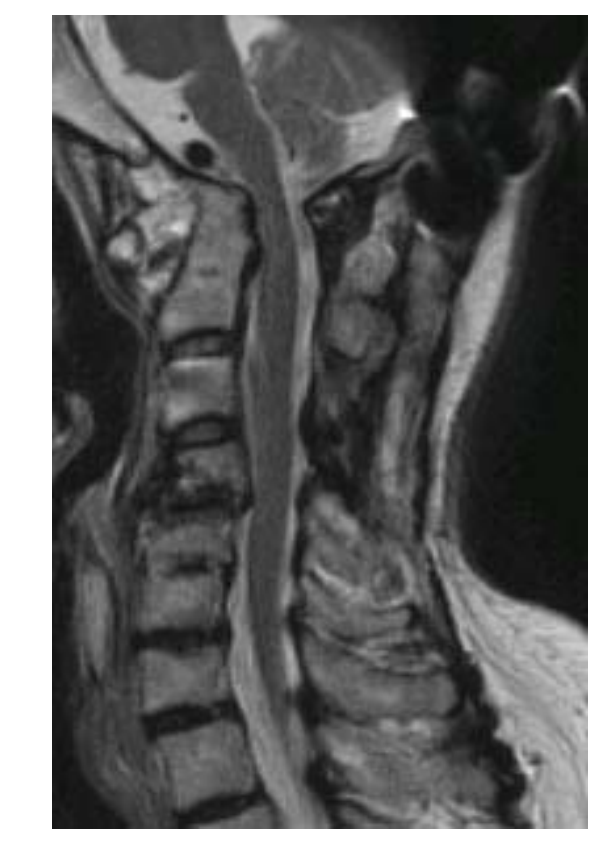

(e) 1 year after surgery

Figure 6 


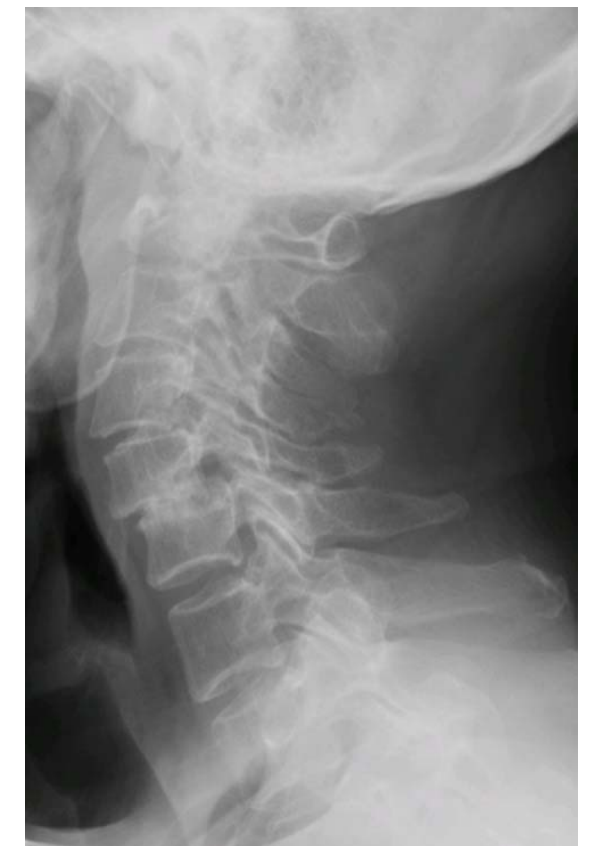

(a) Before surgery

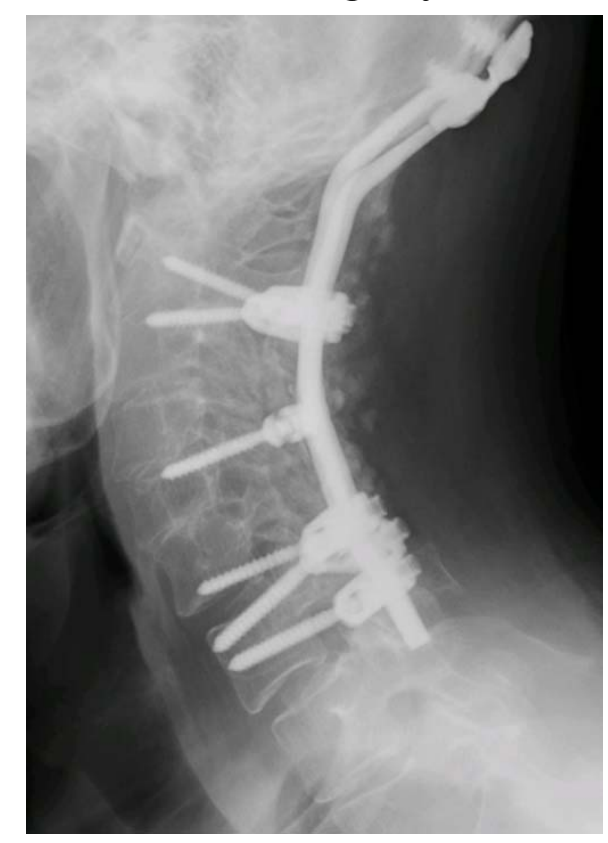

(c) 5 years after surgery

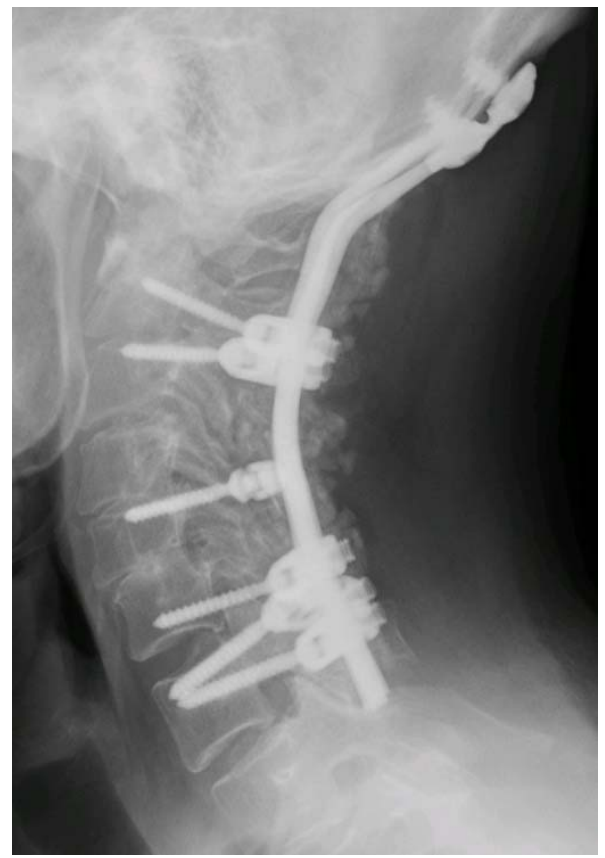

(b) 2 years after surgery

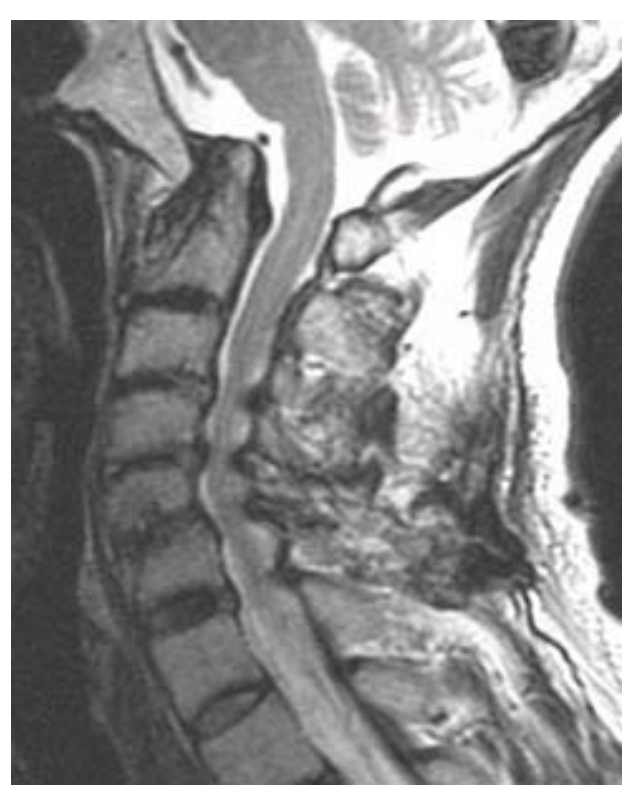

(d) Preoperative MRI 
Table 1. Clinical profile and details of surgical procedures

\begin{tabular}{ccccccccccc}
\hline Case & $\begin{array}{c}\text { Age at surgery } \\
\text { (years) }\end{array}$ & $\begin{array}{c}\text { Gender } \\
\text { RA duration } \\
\text { (years) }\end{array}$ & $\begin{array}{c}\text { Steinbrocker } \\
\text { (stage, class) }\end{array}$ & $\begin{array}{c}\text { Preoperative } \\
\text { JOA score }\end{array}$ & $\begin{array}{c}\text { Preoperative } \\
\text { Ranawat class }\end{array}$ & Medication & Cervical & $\begin{array}{c}\text { Fusion } \\
\text { disorders }\end{array}$ & $\begin{array}{c}\text { Laminectomy } \\
\text { area }\end{array}$ & $\begin{array}{c}\text { Follow-up } \\
\text { or Laminoplasty }\end{array}$ \\
(months)
\end{tabular}

GST: Gold sodium thiomalate, MTX: Methotrexate, PSL: Prednisolone,

AAS: atlantoaxial subluxation, VS: vertical subluxation, SAS: subaxial subluxation, N: no 